\title{
Urothelial Carcinoma Seeding at Site of Nephrostomy
}

\author{
Ala'a Farkouh, Mohammed Shahait ${ }^{\bowtie}$ \\ King Hussein Cancer Center, Department of Surgery, Amman, Jordan
}

A 57-year-old man, with a history of nephrolithiasis and heavy smoking ( 80 pack years at presentation), presented to a tertiary cancer center 2 years ago with urothelial carcinoma (UC) in the right distal ureter associated with lung metastasis. On initial presentation, the patient complained of right flank pain, gross hematuria, and weight loss. Imaging revealed a $3.7 \mathrm{~cm}$ right distal ureter mass with severe right hydronephrosis (Figure 1a) and a $3.2 \mathrm{~cm}$ lung lesion, which was proven by biopsy to be metastatic UC. A right nephrostomy was inserted for palliation of symptoms and to manage recurrent

\section{FIGURE 1A.}

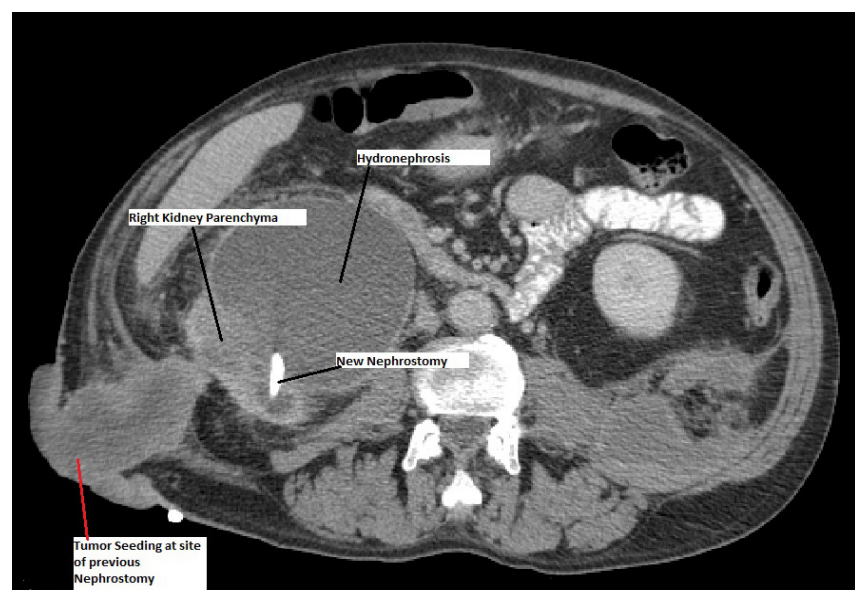

Cross-sectional CT scan showing the tumor extending from the kidney along the previous nephrostomy tract to the skin externally obstructive pyelonephritis. The patient's disease progressed despite multiple lines of chemotherapy and immunotherapy. He developed infection at the nephrostomy site with associated emphysematous pyelonephritis. This was managed with antibiotics and placement of a new nephrostomy at a different site, and palliative nephrectomy was considered. After resolution of the infection, the patient was noted to have a small malodorous mass at the site of the previous nephrostomy that progressively grew in size over 4 months (Figure 1b). Biopsy of the mass revealed UC.

\section{FIGURE 1B.}

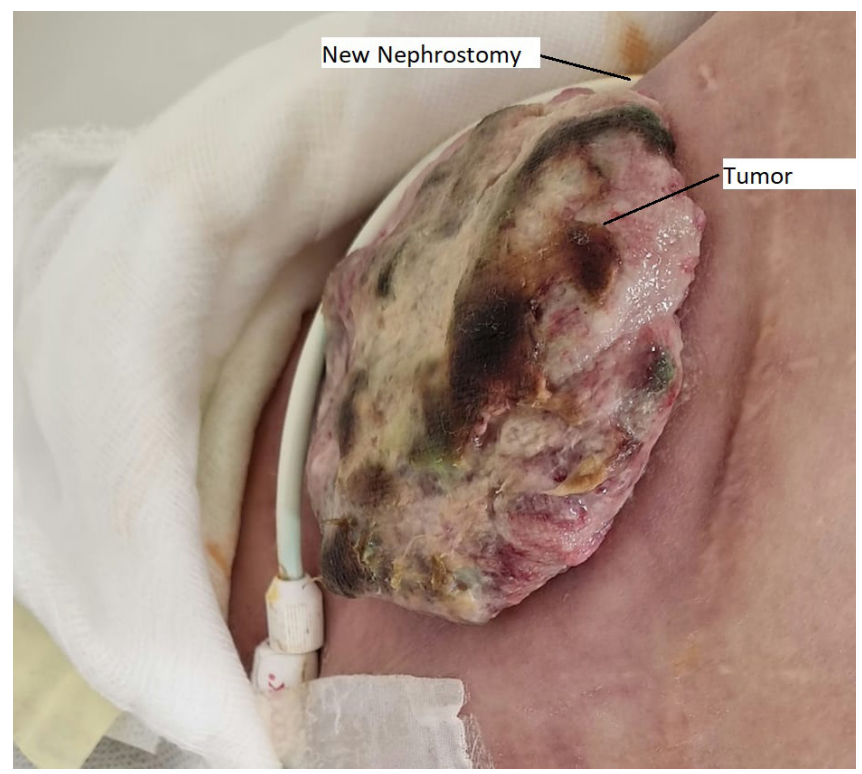

Mass seen at the patient's flank next to the nephrostomy

\section{Key Words}

Transitional cell carcinoma, nephrostomy, tumor seeding

\section{Competing Interests}

None declared.

Patient Consent: Obtained.

\section{Article Information}

Received on September 6, 2021 Accepted on September 17, 2021

Soc Int Urol J.2021;2(6):382

DOI: $10.48083 /$ ZVXI1252 